\title{
Pediction method of rock stratum anti-diamond characteristics of carbonate rocks used in Qinghai YingXi block
}

\author{
ZHANG Guohui, ZHANG Xiwen ${ }^{1}$, CHEN rong ${ }^{1}$, LIU Xinyun, Hugui ${ }^{1}$ \\ PetroChina Research Institute of Petroleum Exploration \& Development, Beijing 100083, China
}

\begin{abstract}
At present domestic drillability prediction is mainly aimed at sandy mudstone formation, The aim is to study less carbonate strata. With the increase of carbonate exploration reserves, the development of carbonate is the main task facing oil companies. This paper has passed the indoor core test, combined with site logging data, research and analysis of mathematical statistics. The relationship between the rock drillability, compressive strength and acoustic jet lag, plasticity coefficient and poisson ratio, and the difference between the surface acoustic jet lag and the time difference between the wave jet and the wave jet were also found. A prediction model is established for predicting the parameters of drilling resistance in carbonate rocks using well logging data. In this paper, the anti-drilling characteristics of carbonate rocks in Yingxi block of Qinghai oilfield are analyzed, Provide reasonable basis for the selection of bit type in the area.
\end{abstract}

\section{Preface}

At present, the domestic drillability prediction is mainly carried out in sandy mudstone formation, and there are few researches on carbonate strata ${ }^{[1-6]}$. With the increasing of carbonate exploration reserves, the development benefit of carbonate has become the main topic of oil company.

The drilling characteristics of stratum include the drillability, abrasion and embrittlement of rock.The parameters of drilling resistance include rock drillability grade, abrasive index and plasticity coefficient.It is an important basis to optimize the drill design and predict the speed of mechanical drilling and the ultimate economic benefit. Research shows that the propagation velocity of sound waves in rock and rock drillability, compressive strength, etc have good correlation, and with the formation lithology, rock structure, buried depth and geological time has a close relationship.

Carbonate rocks are the most important petroleum rich strata in China. The correlation between the acoustic characteristics of rock formation rocks and the parameters of drilling resistance is studied. Establishment of log data to predict the parameters of drilling resistance in carbonate rocks. It is of great economic value and strategic significance to provide reasonable basis for the design of carbonate stratum bit.

\section{Core test}

The core selection collects 12 cores from different depths of the Yingxi block and different geological ages. The lithology includes the dolomite and limestone, which represents the carbonate lithology of the carbonate strata in the YingXi block.

Determination of compressive strength: The single axial compressive strength of each rock sample was determined by uniaxial compressive strength tester.

Determination of rock drillability: Using down III type rock drillability apparatus and standard determination of micro drill bit drillability of rock sample, drill 5 holes in each rock surface, the geometric mean of the drill is the value of the diamond drillability. The calculation formula of drillability level is as follows:

$$
k_{d}=\log _{2} T
$$

In the type, $\mathrm{k} \_\mathrm{d}$ representative rock drillability level value

The longitudinal velocity and shear velocity of rock samples were determined by HF-F intelligent ultrasonic $\mathrm{P} \cdot \mathrm{S}$ comprehensive tester. The rock sample is placed between the two probes, and the ultrasonic wave of the launch probe is received by the receiving probe as it passes through the rock sample, and the electronic signal is displayed on the oscilloscope. Determine the beginning of the first wave and measure the time of the sound wave through the rock sample. If the length of the rock is L, the propagation velocity of sound wave through the rock sample is calculated by $\mathrm{V}=\mathrm{L} / \mathrm{T}$, In the equation of sonic jet lag

$$
\Delta t_{p}=t / L
$$

In the type, $\Delta t \_p$ representative Longitudinal wave time difference. 
The hardness of the rocks: The hardness of the rock was determined by means of rock hardness tester, The plasticity coefficient of rock samples is calculated based on the deformation curve of the pressure test.

Determination of density: The density of each rock sample is determined by weighing method.

\section{The prediction model of anti-diamond characteristic of carbonate rock is established}

\subsection{Test data processing method}

The properties of rock can be drilled, compressive strength, plastic coefficient and rock acoustic properties. Linear functions, mathematical polynomials, exponential functions, power functions, logarithmic functions and other mathematical models are selected. The relationship between drilling grade, compressive strength and plasticity coefficient of carbonate formation rocks is analyzed. The prediction model of the parameters of the anti-drilling characteristic of carbonate rocks is established ${ }^{[7]}$.

\subsection{The prediction model of rock plasticity coefficient is established}

The plastic coefficient of rock is the ratio of the total work before the rock breaking and the elastic deformation work before the rock fracture, It quantitatively represents the size of rock plasticity and brittleness, the experimental data are analyzed, it is found that there is a certain correlation between the rock plasticity coefficient and poisson ratio. The fitting curve is shown in figure 1, and its relation is as follows.

The plastic

coefficient

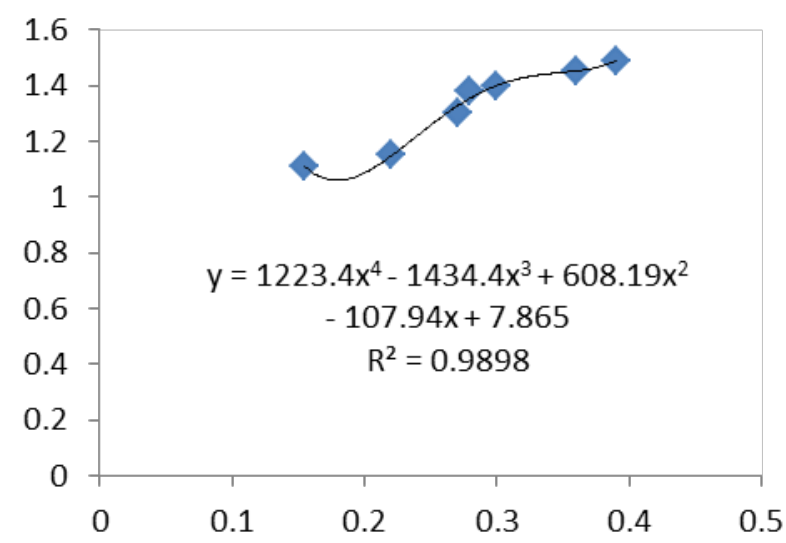

Figure 1. Relationship between plasticity coefficient and Poisson's ratio in carbonate formation.

$\mathrm{K}=1223.4 \mu 4-1434.4 \mu 3+608.19 \mu 2-107.94 \mu+$ $7.865 \quad(\mathrm{R}=0.9898)$

In the type, $\mathrm{K}$ representative rock plasticity coefficient, $\mu$ is Poisson's ratio. The confidence level a
$=0.01$, check the correlation coefficient test form $\mathrm{R}$ $0.01,10=0.75$, as $\mathrm{R}>\mathrm{R} 0.01,10$ formula 3 is high significant.

In practical application on site, it is difficult to obtain the cross-wave jet lag data and poisson is more difficult to find. Based on the horizontal wave difference prediction model of Liu xiang jun from southwest university of petroleum, the theory of the poisson ratio [8] of rock is well calculated. In this article, through indoor rock core test of the time difference, time difference and shear waves with the method of mathematical regression established the relation between the jet lag time and shear waves in carbonate rock layers, according to the logging sonic moveout and density logging data calculation formation rock poisson's ratio, which can predict the plasticity coefficient of rock stratum.The relationship between the time difference and the time difference of the carbonate rock is as follows:

$\Delta t_{S}=1.3625 \Delta t_{p}+80.3264$

In the type, $\Delta \mathrm{tS}$ representative Shear wave time difference

The model of the formation anti-drilling characteristic model needs to establish the relationship model between the acoustic jet lag and the acoustic jet lag. By collecting and testing the same acoustic logging data from the core well and the well. In this paper, the relationship between acoustic jet lag and acoustic jet lag in carbonate strata is established by means of mathematical regression. The relationship between acoustic time difference and log time difference in carbonate formation is as follows:

$$
\Delta \mathrm{t}=5.3625 \Delta t_{p}^{0.7856}
$$

\subsection{The establishment of the prediction model of rock drillability}

In this paper, the method of mathematical statistics is used to determine the rock drillability and indoor acoustic jet lag of indoor core test.Analysis shows that the correlation between the drillability level and the pwave time difference of carbonate formation rocks is better, and both of them are exponential functions. The fitting curve is shown in fig. 2 .

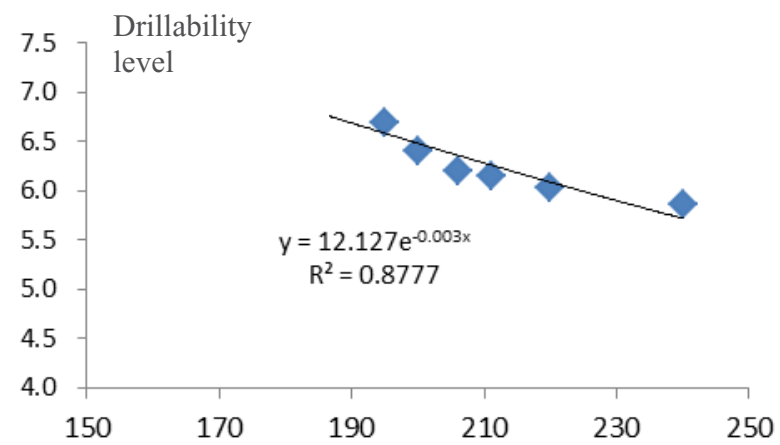

Figure2 Relationship between drillability and compressional wave offset time in carbonate formation 
The relationship model of rock drillability and compressional jet lag in carbonate rocks is as follows:

$$
k_{d}=12.365 e^{-0.004176} \quad(\mathrm{R}=0.8777)
$$

The confidence level $\alpha=0.01$, check the correlation coefficient test form R 0.01, $10=0.65$, as R $>$ R 0.01 , 10 formula 6 is high significant.

\subsection{Establishment of prediction model of rock compressive strength}

In this paper, the results of rock compressive strength and indoor acoustic jet lag were carried out by mathematical statistical methods. The analysis shows that the correlation between compressive strength and compressional time difference of carbonate rocks is good, and the two are power function, and the fitting curve is shown in fig. 2 .

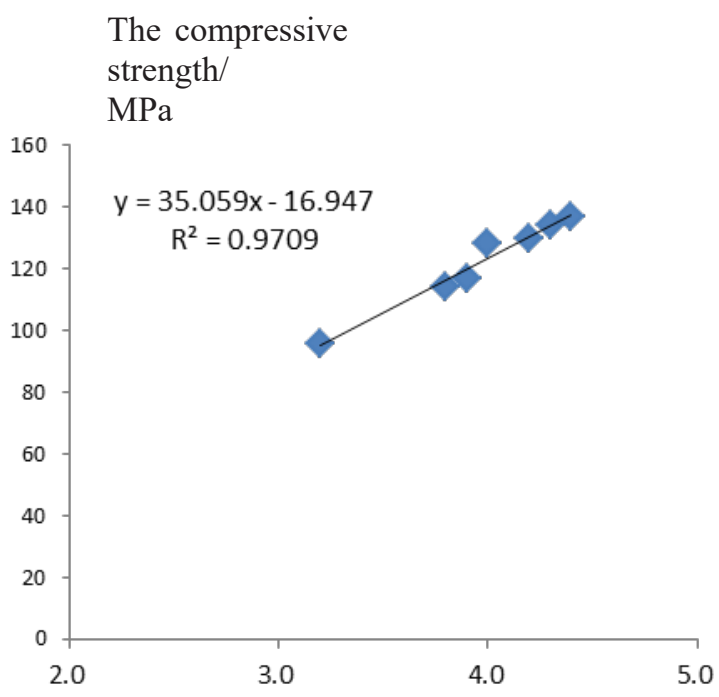

Figure3Relationship between compressive strength and compressional wave offset time in the carbonate formation

The relationship between compressive strength and compressional jet lag of carbonate rocks is shown below:

$\sigma_{c}=35.059\left(300 / \Delta t_{p}\right)^{3}-16.947 \quad(\mathrm{R}=0.9709)$

(7)

In the type, $\Delta \mathrm{tS}$ representative Shear wave time difference

The confidence level $\alpha=0.01$, check the correlation coefficient test form $\mathrm{R} 0.01,10=0.77$, as $\mathrm{R}>\mathrm{R} 0.01$, 10 formula 7 is high significant.

\subsection{Establishment of rock abrasion prediction model}

The prediction method of rock abrasion is relatively small in domestic and international studies. There has not been a single standard method for the determination of rock abrasion. It is shown that the grinding of the crystalline rock is proportional to the hardness of its mineral. In this type of rock, the grinding is in the order of small to large: Gypsum, barite, limestone, dolomite, siliceous rock, feldspar, quartzite.

It is assumed that the abrasion of the crystalline rock is proportional to its composite hardness and compressive strength, and the grinding of crystalline rocks can be calculated according to the calculation

$$
A_{f}=\mathrm{k} \sigma_{c} \mathrm{Y}
$$

In the type : $\mathrm{k}$ is The empirical coefficients associated with lithology, For carbonate rocks $\mathrm{k}=$ 0.005 ; Y Composite hardness of rocks (mohs hardness), by calculation:

$$
\mathrm{Y}=1 / \sum_{1}^{m} \frac{v_{i}}{y_{i}}
$$

In the type: $\quad \mathrm{v} i \mathrm{i}$ the volume of the ith minerals, $y_{-} i$ :degree of mohs hardness of type ith minerals.In this paper, the volume content of minerals can be obtained by means of two mineral rock interpretation models.

3.6 Validation and results of the model

In order to verify the accuracy of the established parameters prediction model of the stratum. In addition, a total of 12 rock samples were selected, and the measured anti-drilling characteristic data was compared with the model prediction results. The results were shown in table 1 (include table1-1 、 table 1-2 table 1-3)

Table 1 Test results of prediction model for carbonate

\begin{tabular}{|c|c|c|c|}
\hline \multirow[b]{2}{*}{$\begin{array}{r}\text { The } \\
\text { lithology }\end{array}$} & \multicolumn{3}{|c|}{ Drillability level } \\
\hline & $\begin{array}{c}\text { The } \\
\text { value } \\
\text { determination }\end{array}$ & $\begin{array}{c}\text { Predictive } \\
\text { value }\end{array}$ & $\begin{array}{l}\text { error } \\
\quad / \% \\
\end{array}$ \\
\hline dolomite & 6.35 & 6.15 & 3.25 \\
\hline dolomite & 6.22 & 6.41 & 2.96 \\
\hline dolomite & 6.55 & 6.73 & 2.67 \\
\hline dolomite & 6.21 & 6.09 & 1.97 \\
\hline dolomite & 6.39 & 6.22 & 2.73 \\
\hline dolomite & 6.54 & 6.95 & 5.90 \\
\hline limestone & 6.21 & 6.47 & 4.02 \\
\hline limestone & 5.99 & 6.42 & 6.70 \\
\hline limestone & 5.94 & 5.49 & 8.20 \\
\hline limestone & 5.46 & 5.29 & 3.21 \\
\hline limestone & 5.58 & 5.35 & 4.30 \\
\hline limestone & 5.76 & 5.51 & 4.54 \\
\hline \multicolumn{4}{|c|}{ (Table 1-2 } \\
\hline \multicolumn{4}{|c|}{ The compressive strength } \\
\hline $\begin{array}{r}\text { The } \\
\text { lithology }\end{array}$ & $\begin{array}{c}\text { The } \\
\text { value } \\
\text { determination }\end{array}$ & $\begin{array}{c}\text { Predictive } \\
\text { value }\end{array}$ & $\begin{array}{l}\text { error } \\
\quad / \% \\
\end{array}$ \\
\hline dolomite & 216.35 & 209.39 & 3.32 \\
\hline dolomite & 245.32 & 222.19 & 10.41 \\
\hline dolomite & 218.88 & 231.24 & 5.35 \\
\hline dolomite & 236.43 & 215.36 & 9.78 \\
\hline dolomite & 215.49 & 200.31 & 7.58 \\
\hline dolomite & 222.75 & 195.21 & 14.11 \\
\hline limestone & 210.65 & 201.37 & 4.61 \\
\hline limestone & 198.75 & 220.3 & 9.78 \\
\hline limestone & 204.11 & 198.62 & 2.76 \\
\hline limestone & 232.54 & 229.63 & 1.27 \\
\hline limestone & 245.05 & 239.61 & 2.27 \\
\hline limestone & 236.15 & 230.01 & 2.67 \\
\hline
\end{tabular}
formation

(Table 1-1) 
( Table 1-3)

\begin{tabular}{r|rcc}
\hline \multirow{2}{*}{\begin{tabular}{r} 
The \\
\cline { 2 - 4 } lithology
\end{tabular}} & $\begin{array}{c}\mid c \\
\text { The plastic coefficient } \\
\text { value } \\
\text { determination }\end{array}$ & $\begin{array}{c}\text { Predictive } \\
\text { value }\end{array}$ & $\begin{array}{c}\text { error } \\
\text { /\% }\end{array}$ \\
\hline dolomite & 1.533 & 1.468 & 4.43 \\
dolomite & 1.547 & 1.552 & 0.32 \\
dolomite & 1.362 & 1.306 & 4.29 \\
dolomite & 1.369 & 1.352 & 1.26 \\
dolomite & 1.485 & 1.441 & 3.05 \\
dolomite & 1.444 & 1.398 & 3.29 \\
limestone & 1.396 & 1.421 & 1.76 \\
limestone & 1.392 & 1.362 & 2.20 \\
limestone & 1.462 & 1.451 & 0.76 \\
limestone & 1.487 & 1.467 & 1.36 \\
limestone & 1.265 & 1.288 & 1.79 \\
limestone & 1.362 & 1.332 & 2.25 \\
\hline
\end{tabular}

From table 1, the value of rock drillability grade, compressive strength and plasticity coefficient of forecasting precision are reached about $90 \%$, shows that the established drilling parameters to predict the accuracy of the models, can meet the needs of the project.

\section{Analysis of the anti-drilling characteristics of the strata in Yingxi block of qinghai}

The Yingxi block of qinghai province is located in the northwest of the hero ridge in chaidam basin, and is 3000 $\sim 3900 \mathrm{~m}$ above sea level. Oilfield from the top to drill in $\mathrm{N}_{2}{ }^{2}, \mathrm{~N}_{2}{ }^{1}, \mathrm{~N}^{1}, \mathrm{E}_{3}{ }^{2}$ four strata, $\mathrm{N} 1$ upper distribution in the lower part to $\mathrm{E}_{3}{ }^{2}$ composite salt-gypsum layer, buried depth, 3500 4700m, salt for sand shale formation, presalt carbonate formation. Reservoir pressure coefficient is $1.3 \sim 2.0$, geothermal gradient $3 \sim 3.25^{\circ} \mathrm{C} / 100 \mathrm{~m}$.

Field collection of drilling data and logging data, according to the established formation drilling resistance characteristic parameters parameter prediction model, the Marine strata of rock compressive strength, drilling, grinding and plasticity coefficient of the calculation and analysis. In this paper, the drilling properties of the block are established by using the self-developed stratigraphic drilling software (see figure 4). The results of the comprehensive analysis of the formation anti-drilling properties in Yingxi block of Qinghai oilfield are shown in table 2 (include table 2-1、table 2-2 、 table 2-3、 table 2-4)

Table 2 Results of anti-drilling parameters for carbonate formation in Yingxi block

( Table2-1)

\begin{tabular}{c|cc}
\hline \multirow{2}{*}{ Formation } & \multicolumn{2}{|c}{ The compressive strength /MPa } \\
\cline { 2 - 3 } & average & Average square error \\
\hline \multirow{2}{*}{$\mathrm{N}_{1}$} & 198.75 & 0.53 \\
& -231.24 & -1.46 \\
$\mathrm{E}_{3}{ }^{2}$ & 215.49 & 0.98 \\
& -245.32 & -2.11
\end{tabular}

( Table2-2)

\begin{tabular}{|c|c|c|}
\hline \multirow[b]{2}{*}{ Formation } & \multicolumn{2}{|c|}{ Drillability level } \\
\hline & average & average square error \\
\hline \multirow[b]{2}{*}{$\mathrm{N}_{1}$} & 5.46 & 0.24 \\
\hline & -6.39 & -0.55 \\
\hline \multirow{3}{*}{$\mathrm{E}_{3}{ }^{2}$} & 5.76 & 0.18 \\
\hline & -6.22 & -0.80 \\
\hline & & (Table2-3) \\
\hline \multirow[b]{2}{*}{ Formation } & \multicolumn{2}{|c|}{ Abrasive index } \\
\hline & average & average square error \\
\hline \multirow{3}{*}{$\mathrm{N}_{1}$} & 3.15 & 0.39 \\
\hline & -3.68 & -0.88 \\
\hline & 2.75 & 0.47 \\
\hline $\mathrm{E}_{3}{ }^{2}$ & -4.08 & -0.86 \\
\hline
\end{tabular}

( Table2-4)

\begin{tabular}{c|cc}
\hline \multirow{2}{*}{ Formation } & \multicolumn{2}{|c}{ The plastic coefficient } \\
\cline { 2 - 3 } & average & average square error \\
\hline & 1.26 & 0.39 \\
$\mathrm{~N}_{1}$ & -1.53 & -0.79 \\
\hline & 1.36 & 0.47 \\
$\mathrm{E}_{3}{ }^{2}$ & -1.48 & -0.89 \\
\hline
\end{tabular}

As can be seen from table 2, the carbonate strata in the in Yingxi block have the following characteristics High strength, poor drillability. Compressive strength $145.7 \sim 259.1 \mathrm{MPa}$; Rock drillability level $5.46 \sim 6.39$.

Less abrasive. The abrasion index of each stratum was $3.15 \sim 4.08$.

The stratigraphic uniformity is high, and the variation range of compressive strength, drillability level and abrasive index of different strata is small.

The formation rocks are brittle. The plasticity coefficient of each formation is $1.25 \sim 1.53$. Through the analysis of the Yingxi block block formation drilling resistance characteristics, can be seen that the Yingxi block formation rock drillability grade value is higher, but less abrasive, stratigraphic homogeneous degree is high, suitable for chunks of PDC bit drilling. At the same time, in order to increase the number of cutting times of PDC bit to the formation and improve the drilling efficiency, it is recommended to use the screw drilling tool in the process of carbonate formation drilling to cooperate with PDC bit drilling. The results show that the average mechanical drilling rate increases by $60 \% \sim 80 \%$ in the process of composite drilling, and $40 \% \sim 70 \%$ of the drill bit is increased by a single bit, which is very obvious.

\section{Conclusion and cognition}

5.1 The correlation between the drillability of carbonate rocks and the p-wave jet lag is good, and the two are exponential. The rock abrasion is proportional to its compressive strength and hardness. The relationship between rock plasticity coefficient and poisson ratio is better, and the relationship between the two is polynomial function. 
5.2 The surface acoustic carbonate strata and the power function of the borehole acoustic wave are difference; The p-wave time difference is a linear function of the time difference.

5.3The established prediction model was verified by the results of laboratory test. The results show that the prediction accuracy is high and can meet engineering requirements.

5.4 Using the established carbonate formation drilling resistance characteristic parameter prediction model can better analyze the Yingxi block drilling resistance characteristics of Marine strata, carbonate strata in this area.This methed can optimize the design of the drill bit type and drilling parameters, which provide reasonable basis, for efficient reasonable development of the carbonate formation oil and gas resources in China has important guidance and reference significance.

\section{References}

1. YIN Hongjin. Analysis of rock drillability[M].Dongying : China University of Petroleum Press,1989:12-25.(in Chinese)

2. SOMERTONW H. Further studies of the relation of physical properties of rock to rock drill ablity[J]. SPE 2390,1969.

3. GSTALDERS,RAYNAL J. Measurement of some mechanical properties of rock and their relationship to drillability[J]. SPE 1463,1966.

4. LIU Ronghe,FENG Wenguang. Experimental studies on the mechanics and acoustics of tight carbonate rock[J]. Petroleum Geology and Oilfield Development in Daqing,2008,27(12) : 131-135.(in Chinese)

5. ZOU Deyong,CHENG Yuanfang. Rock-drill ability evaluation and bit selection through ultrasonic velocity measurement on cutting[J].Journal of China University of Petroleum: Natural Science, 2005, 29(1): 36-40.(in Chinese))

6. WANG Kexiong,WEI Fengqi.Applications of logging information in predicting formation antidrilling parameters[J].Petroleum Drilling Techniques,2003,31(5):61-62.(in Chinese)

7. CHANG Zhaoguang, WANG Qinghe.The statistical method[M]. Dongying : China University of Petroleum Press, 2005: 107-135.(in Chinese)

8. LIU Xiangjun, HAN Lin. Experimental research on the elastic modulus and Poissong's ratio based on the acoustic time[J].Journal of Southwest University of Pertroleum,2007,29(8): 19-22.(in Chinese) 